\title{
Development of Fertilizer Broadcaster with Electronically Controlled Fluted Roller Metering Mechanism for Paddy Crop
}

\author{
Edwin Benjamin $^{1}$, D. Anatha Krishnan ${ }^{2}$ and R. Kavitha ${ }^{2}$ \\ ${ }^{1}$ Department of Agriculture Engineering, Sri Shakthi Institute of Engineering and Technology, \\ Coimbatore, India \\ ${ }^{2}$ Tamil Nadu Agricultural University, Coimbatore, India \\ *Corresponding author
}

\section{Keywords}

Fertilizer

broadcasters, Side shaft high torque DC motor, Fluted roller, Spreading unit, Field capacity

Article Info

Accepted:

20 March 2019

Available Online:

10 April 2019

\section{A B S T R A C T}

Traditional type fertilizer broadcasters were with constant opening with gravity flow method which was showing high variation in discharge quantity of fertilizer between the rows and this lead to under and over dosage. A battery operated variable rate fertilizer broadcaster was developed and it consisting of storage tank, metering unit, spreading unit and variable rate controller unit was developed. To standardize the metering mechanism for the fertilizer applicator, a study was conducted on the existing fertilizer metering devices. Based on the literatures, fluted roller feeding mechanism was selected for the development of fertiliser applicator, since the positive feeding mechanism results in accurate variations of the discharge rate by adjusting the exposed length of the fluted roller. The performance evaluation of the developed variable rate fertilizer broadcaster was conducted in laboratory to confirm its discharge in various exposure lengths of fluted roller as well as the spread pattern test to measure the coefficient of variation which is used to determine and express the uniformity of distribution of the application. It was observed that the application rate of $28,64,95$ and $140 \mathrm{~kg} \mathrm{ha}^{-1}$ could be achieved for 10,20,30 and $40 \mathrm{~mm}$ exposure length of flute respectively. The coefficients of variation were $3.95,2.94$, 3.82 and 2.66 per cent in application rates for 10, 20,30 and $40 \mathrm{~mm}$ exposure length of flute respectively. The actual field capacity of the developed unit was observed as 0.30 ha $\mathrm{h}^{-1}$. The efficiency of the machine is 83 per cent.

\section{Introduction}

In traditional system, the broadcaster was used in the paddy field for spreading fertilizer and seeds. All fertilizer broad casters were with constant opening with gravity feed method. This type of fertilizer broadcasters was showing high variation in discharge quantity of fertilizer between the rows and this lead to under and over dosage. So a positive feed mechanism based metering system for a broadcaster was developed with variable rate adjustment. Variable rate technology (VRT) of inputs is an important component of precision agriculture that results in reduction of inputs. Also it enables 
the reduction in agrochemicals and fertilizer application along with a positive environmental impact (Ganesh 2009). The recent studies on injector-type applicator showed that the push-type applicator significantly reduced the labor requirement to 15-20 h/ha compared to the injector-type applicator or hand placement (Abdul Wohab et al., 2017).

Wolf and Smith (1979) developed a hand held rotary spinning spreader. Tests were conducted in two different carrying positions and travel patterns in the field conditions. Varshney et al., (1967) developed a hand operated centrifugal broadcaster suitable for Indian conditions based on the imported broadcaster from USA. The results showed similarity in distribution pattern in some of the seeds due to same similar physical property. The recent studies on injector-type applicator showed that the push-type applicator significantly reduced the labor requirement to $15-20 \mathrm{~h} / \mathrm{ha}$ compared to the injector-type applicator or hand placement (Abdul Wohab et al., 2017). Applying fertilizer evenly can reduce crop input costs and dramatically improve crop yields and performance (Anonymous 2016).The present study was undertaken with the specific objective to develop a broadcaster with variable rate technology.

\section{Materials and Methods}

To standardize the metering mechanism for the fertilizer applicator, a study was conducted on the existing fertilizer metering devices. Based on the literatures, fluted roller feeding mechanism was selected for the development of fertiliser applicator, since the positive feeding mechanism results in accurate variation of the discharge rate by adjusting the exposed length of the fluted roller. Number of flutes and speed of rotation of rotor were selected based on the data book,
Agricultural Machinery Design and Data Handbook (seeders and planters) by RNAM 1991. The machine parameter viz. Number of flutes, Length of the flute exposed and rotational speed influence the discharge rate of fertilizer. These machine parameters have to be optimized to achieve the precise application and proper uniformity distribution of fertilizer applicator. Hence these parameters were selected for the laboratory investigation. The final prototype made by laboratory optimization and a Regression model was developed for exposure length based on the required application rate

\section{Development of variable rate fertilizer broadcaster}

The newly developed machine consists of the following main components,

Storage tank or Hopper

Metering unit

Spreading unit

Variable rate Controller Unit

\section{Storage tank or Hopper}

The storage tank was fabricated using acrylic pipe and aluminium sheet. A acrylic pipe having $200 \mathrm{~mm}$ diameter $5 \mathrm{~mm}$ thickness and $300 \mathrm{~mm}$ height. A $2 \mathrm{~mm}$ thick aluminium sheet was used for the fabrication of funnel which is inserted to the acrylic pipe. The funnel has $100 \mathrm{~mm}$ total height and $80 \mathrm{~mm}$ slanting height. It has $185 \mathrm{~mm}$ top diameter and $40 \mathrm{~mm}$ bottom diameter. The funnel was inserted in the acrylic pipe and fixed by screw on its periphery. The funnel bottom and acrylic pipe bottom were in line. These whole arrangements were fixed on a acrylic rectangular sheet of size $350 \times 220 \times 6 \mathrm{~mm}$ by using $\mathrm{L}$ angle. A $20 \times 40 \mathrm{~mm}$ sized hole was made on this rectangle sheet coinciding with the funnel bottom. 


\section{Metering unit}

The metering unit consists of different components like main shaft, fluted roller, covering pipe, rack and pinion mechanism and fluted roller housing. The modified fluted roller metering unit components and it arrangements are shown in figure 1 .

\section{Main shaft}

A polished pipe was taken as main shaft in which the fluted roller was inserted. The shaft has $220 \mathrm{~mm}$ length and $8 \mathrm{~mm}$ diameter. The fluted roller was fixed on the shaft using grip screw. One end of the shaft was directly coupled with motor shaft and other end fixed in bearing.

\section{Fluted roller}

Fluted roller was made of acrylic material with $50 \mathrm{~mm}$ diameter and $50 \mathrm{~mm}$ length. The roller was mounted on a main shaft of $8 \mathrm{~mm}$ diameter. The roller having grooves for their entire length and its shape was semi circular with $5 \mathrm{~mm}$ radius. Both the ends of the fluted roller were plugged with $2 \mathrm{~mm}$ thick acrylic sheet to avoid fertilizer leak through the ends. The fluted roller was fixed on main shaft by a grip screw and main shaft was attached with a high torque side shaft. $12 \mathrm{~V}$ DC motor having square gear box with $50 \mathrm{rpm}$ was used.

\section{Covering pipe}

A covering pipe arrangement was made with PVC pipe of $54 \mathrm{~mm}$ diameter and $70 \mathrm{~mm}$ length. One side of the pipe is plugged with acrylic sheet Plate. The fluted roller easily moves inside the pipe and covers the flutes. The covering pipe was placed on the same shaft in which the fluted roller was place. So the fluted roller exposure length can be achieved by movement of this pipe over a fluted roller.

\section{Rack and pinion mechanism}

A rack and pinion is a type of liner actuator that comprises a pair of gears which convert rotational motion into linear motion. The same mechanism used in this prototype for the movement of the covering pipe which adjusts the exposure length of the fluted rollers. The exposure length will adjust based on our requirements. The maximum exposure length was decided based on lab studies as 40 $\mathrm{mm}$ and minimum opening was $10 \mathrm{~mm}$. So the rack and pinion was designed based on these criteria. Pinion total diameter was 36 $\mathrm{mm}$, and the pinion pitch diameter was 34 $\mathrm{mm}$. The rack pitch distance was $18 \mathrm{~mm}$ and linear pitch distance was $3.5 \mathrm{~mm}$. The spur gear having module no 1.13 was used as pinion.

The pinion gear was driven by a high torque side shaft $12 \mathrm{~V}$ DC motor having square gear box with $10 \mathrm{rpm}$. It has a gear box which was built to handle the stall torque produced by motor. Motor runs smoothly from $4 \mathrm{~V}$ to $12 \mathrm{~V}$ and gives $10 \mathrm{rpm}$ at $12 \mathrm{~V}$. Motor has $8 \mathrm{~mm}$ diameter, $19 \mathrm{~mm}$ length drive shaft with $\mathrm{D}$ shape coupling.

\section{Spreading unit}

Spreading unit consists of disc with four straight fins, 12V DC motor and holding mechanism. The disc made by acrylic sheet of $4 \mathrm{~mm}$ thickness and other dimension of the disc was as per the existing conventional broadcaster. The diameter was $180 \mathrm{~mm}$ with four straight vanes. A $12 \mathrm{~V}$ DC motor was attached to the disc from the bottom which drives the disc at a speed of $400 \mathrm{rpm}$. All the components were mounted on a $\mathrm{L}$ shaped metallic frame. A half round aluminium plate was provided at the back side of the disc for preventing the material leakage through back side. The figure 2 shows the developed metering unit and spreading unit. 


\section{Variable rate controller unit}

The discharge of the Variable rate fertilizer broadcaster was controlled by this controlling unit. The exposure length of the fluted roller was adjusted through rack and pinion mechanism by the coded program which was entered in to the microcontroller. The main components of variable rate controller unit were PIC 16F877 A microcontroller and motor driven controller. PIC 16F877A microcontroller was used in the variable rate controller unit. The PIC 16F877A is one of the most advanced microcontrollers from Microchip. Dual Full Bridge Driver-L298 was used as a motor drive controller. The L298 is an integrated monolithic circuit in a 15- lead Multi watt and Power SO20 packages. It is a high voltage, high current dual full-bridge driver designed to accept standard TTL logic levels and drive inductive loads such as relays, solenoids, DC and stepping motors. These motor drive controls the metering unit movement and rotation of the disc.

The metering unit, spreading unit and Variable rate controller unit were partially closed by acrylic sheet box and aluminum frame. The front side of the spreading unit was open for material discharge. The Developed variable rate fertilizer broadcaster is shown in figure 3 .

\section{Performance evaluation of the developed variable rate fertilizer broadcaster}

The performance evaluation of the developed variable rate fertilizer broadcaster was conducted in laboratory to confirm its discharge in various exposure length of fluted roller as well as the spread pattern test to measure the coefficient of variation which is used to determine and express the uniformity of distribution of the application. The test procedure was followed as per the ASABE standards S341.3 FEB04 (procedure for measuring distribution uniformity and calibrating granular broadcast spreaders). The mean value, standard deviation and $\mathrm{CV}$ were determined (ASABE standard 2005; 2009).

\section{Analysis of economic efficacy of the} variable rate fertilizer broadcaster

The cost of operation and field capacity of the variable rate fertilizer broadcaster was calculated and the economic advantage of the developed target actuated sprayer was analyzed.

\section{Results and Discussion}

The discharge rate of developed metering mechanism was examined under laboratory condition. A variable rate disc spreader was designed and its spread pattern, spreading uniformity coefficient and spread width was evaluated. The field evaluation and collection of various operational parameters of the developed equipment were measured.

\section{Design consideration of the variable rate fertilizer broadcaster}

According to the variable rate fertilizer broadcaster design consideration, a prototype model of broadcaster with a variable rate metering system was developed. The output of the fertilizer was designed for three or four split application. The adopted regression model for the development of the metering unit is shown in figure 4 and the exposure length was designed according to the regression formula $L=0.027 Q+0.183$, it have $\mathrm{R}^{2}$ value 0.997 . Here $\mathrm{L}$ is the exposure length of the fluted roller and $Q$ is the quantity of fertilizer delivered.

\section{Development of variable rate fertilizer broadcaster}

Based on the statistical analysis of different variables in the laboratory, the optimized values were selected and also the desired 
application rate of fertilizer was considered for the development of variable rate fertilizer broadcaster. The detailed specification of each components of the fertilizer broadcaster is presented in Table 1 .

\section{Performance evaluation of the developed fertilizer broadcaster}

The developed prototype was evaluated for its performance in accordance with ASAE S341 "Procedure for Measuring Distribution Uniformity and Calibration of Broadcaster Spreaders" (ASABE standard 1999; 2000; 2005; 2009).

The collection pans were place at $1000 \times 500$ mm spacing (Fig. 5). Total test area was $10 \mathrm{~m}$ x $5 \mathrm{~m}$ and a space of $1000 \mathrm{~mm}$ was provided at center as applicator path. So the distance covered was $10 \mathrm{~m}$ and swath spacing was 2 $\mathrm{m}$. The application rate was calculated for the different exposure length of fluted roller of the developed prototype i.e. 10, 20, 30 and 40 $\mathrm{mm}$. The unit was tested at an average walking speed of $1.2 \mathrm{~km} \mathrm{~h}^{-1}$. The coefficient of variation and effective swath width was calculated. Figure 6 represents the graphical representation of spread patter in one direction of application method for different openings.

From the results of the evaluation of prototype, it is observed that the application rate of 28, 64, 95 and $140 \mathrm{~kg} \mathrm{ha}^{-1}$ could be achieved for the exposure length of flute 10 , 20,30 and $40 \mathrm{~mm}$ respectively.

Table.1 Specification of each parts of the fertilizer broadcaster

\begin{tabular}{|c|c|c|}
\hline Component of Developed & \multicolumn{2}{|l|}{ Specification } \\
\hline \multirow[t]{4}{*}{ Storage tank or Hopper } & $\begin{array}{l}\text { Storage tank } \\
\text { Total height of the tank, mm }\end{array}$ & 300 \\
\hline & Diameter, mm & 200 \\
\hline & Wall thickness, mm & 5 \\
\hline & $\begin{array}{l}\text { Material(Storage tank) } \\
\text { Material(Top lid) } \\
\text { Funnel } \\
\text { Material } \\
\text { Height, mm } \\
\text { Slanting height, mm } \\
\text { Top diameter, mm } \\
\text { Bottom diameter, mm } \\
\text { Sheet thickness, mm }\end{array}$ & $\begin{array}{l}\text { Acrylic pipe } \\
\text { Aluminium sheet } \\
\text { Aluminium sheet } \\
100 \\
80 \\
185 \\
40 \\
2\end{array}$ \\
\hline Metering unit & $\begin{array}{l}\text { Main shaft } \\
\text { Length, mm } \\
\text { diameter, mm } \\
\text { Material } \\
\text { Motor coupled with main shaft } \\
\text { rpm } \\
\text { Fluted roller } \\
\text { Length, mm } \\
\text { Diameter, mm }\end{array}$ & $\begin{array}{l}220 \\
8 \\
\text { Stainless steel } \\
50 \mathrm{rpm}, 12 \mathrm{~V} \text { DC motor } \\
50 \\
50 \\
2\end{array}$ \\
\hline
\end{tabular}




\begin{tabular}{|c|c|c|}
\hline & $\begin{array}{l}\text { End cap thickness, mm } \\
\text { Material } \\
\text { Flute } \\
\text { Shape } \\
\text { Length, mm } \\
\text { depth, mm } \\
\text { Covering pipe } \\
\text { Diameter, mm } \\
\text { Length, mm } \\
\text { Material } \\
\text { Linear movement } \\
\text { Mechanism } \\
\text { Maximum movement, mm } \\
\text { Minimum movement, mm } \\
\text { Spur gear module } \\
\text { Pinion diameter, mm } \\
\text { Pitch diameter, mm } \\
\text { Rack pitch distance, mm } \\
\text { Liner pitch distance, mm } \\
\text { Motor }\end{array}$ & $\begin{array}{l}\text { Acrylic } \\
\text { Semi circular } \\
50 \\
5 \\
54 \\
70 \\
\text { PVC } \\
\text { Rack and Pinion } \\
40 \\
10 \\
1.13 \\
36 \\
34 \\
18 \\
3.5 \\
10 \text { rpm, 12V DC motor }\end{array}$ \\
\hline Spreading unit & $\begin{array}{l}\text { Disc } \\
\text { Diameter, mm } \\
\text { Material } \\
\text { Thickness, mm } \\
\text { Motor }\end{array}$ & $\begin{array}{l}200 \\
\text { acrylic sheet } \\
4 \\
400 \mathrm{rpm}, 12 \mathrm{~V} \mathrm{DC} \\
\text { motor }\end{array}$ \\
\hline Variable rate Controller Unit & $\begin{array}{l}\text { Microcontroller } \\
\text { Motor drive controller }\end{array}$ & $\begin{array}{l}\text { PIC 16F877A } \\
\text { Dual Full Bridge } \\
\text { Driver-L298 }\end{array}$ \\
\hline $\begin{array}{l}\text { Total tank capacity, } \mathrm{kg} \\
\text { Total weight of the unit, kg } \\
\text { Power Source }\end{array}$ & & $\begin{array}{l}5.5 \\
4 \\
\text { Battery }\end{array}$ \\
\hline
\end{tabular}

Fig.1 Modified fluted rollers type metering mechanism

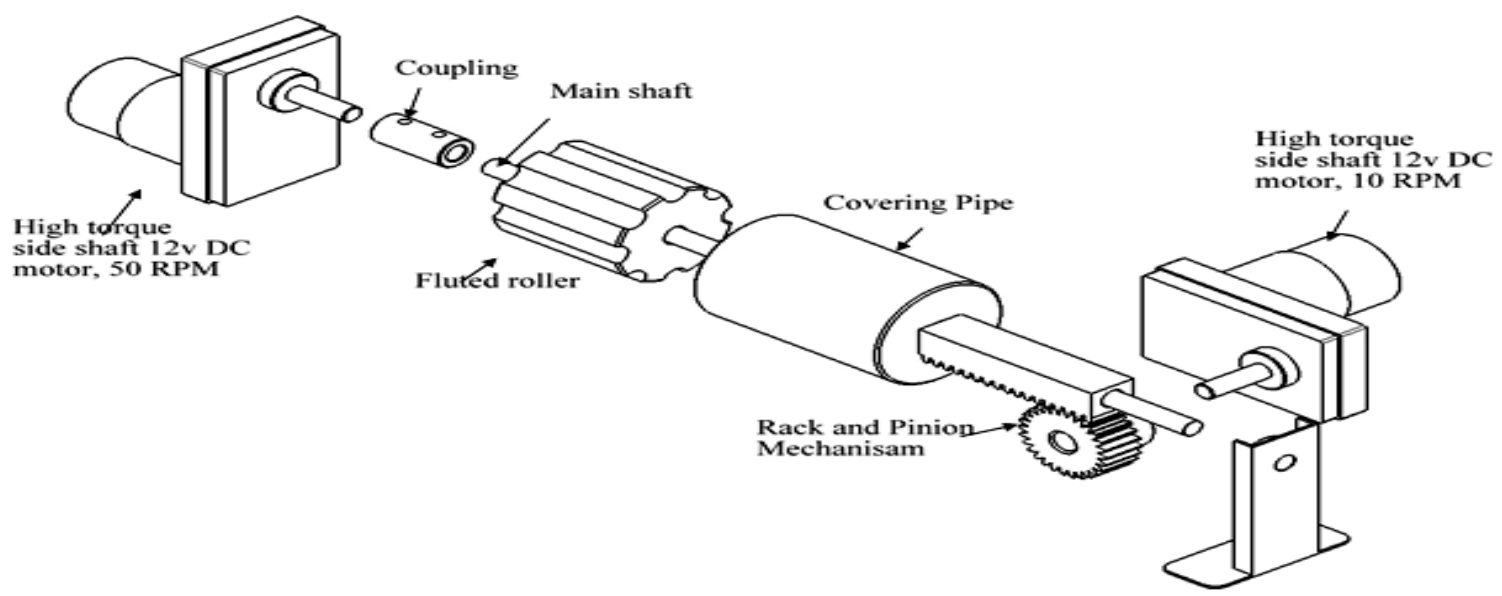


Fig.2 Metering and spreading unit

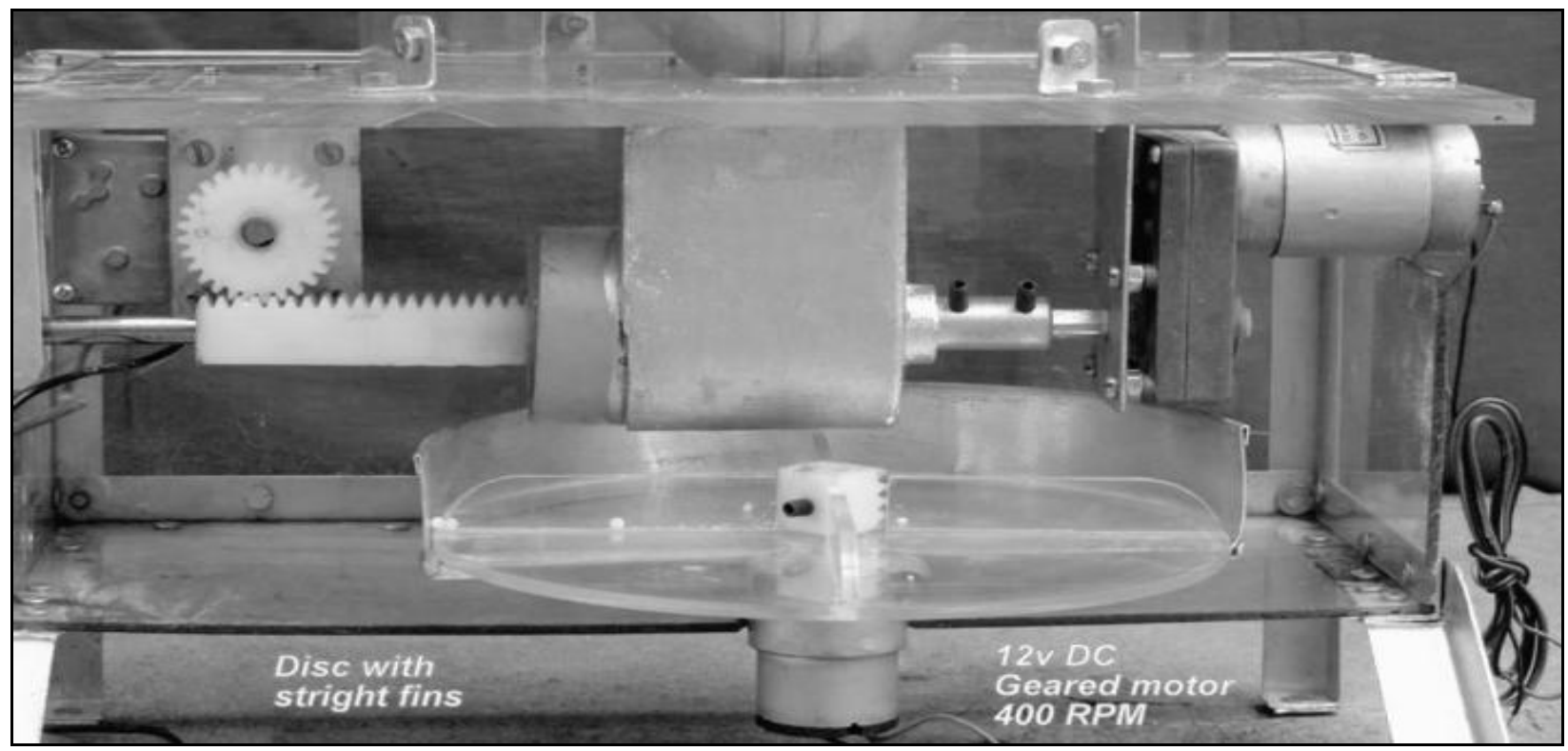

Fig.3 The Developed variable rate fertilizer broadcaster

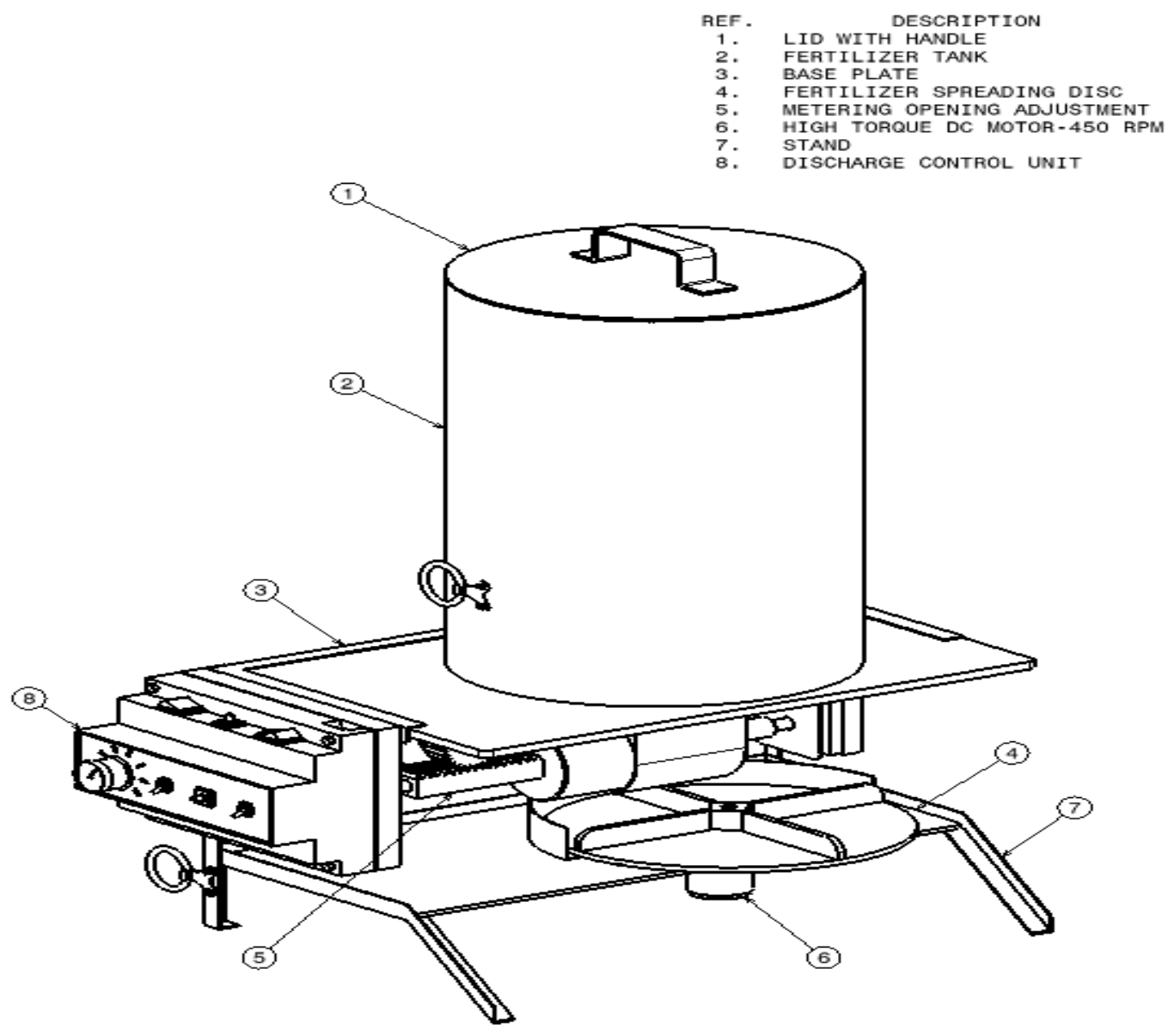


Fig.4 Regression model for exposure length based on the required application rate

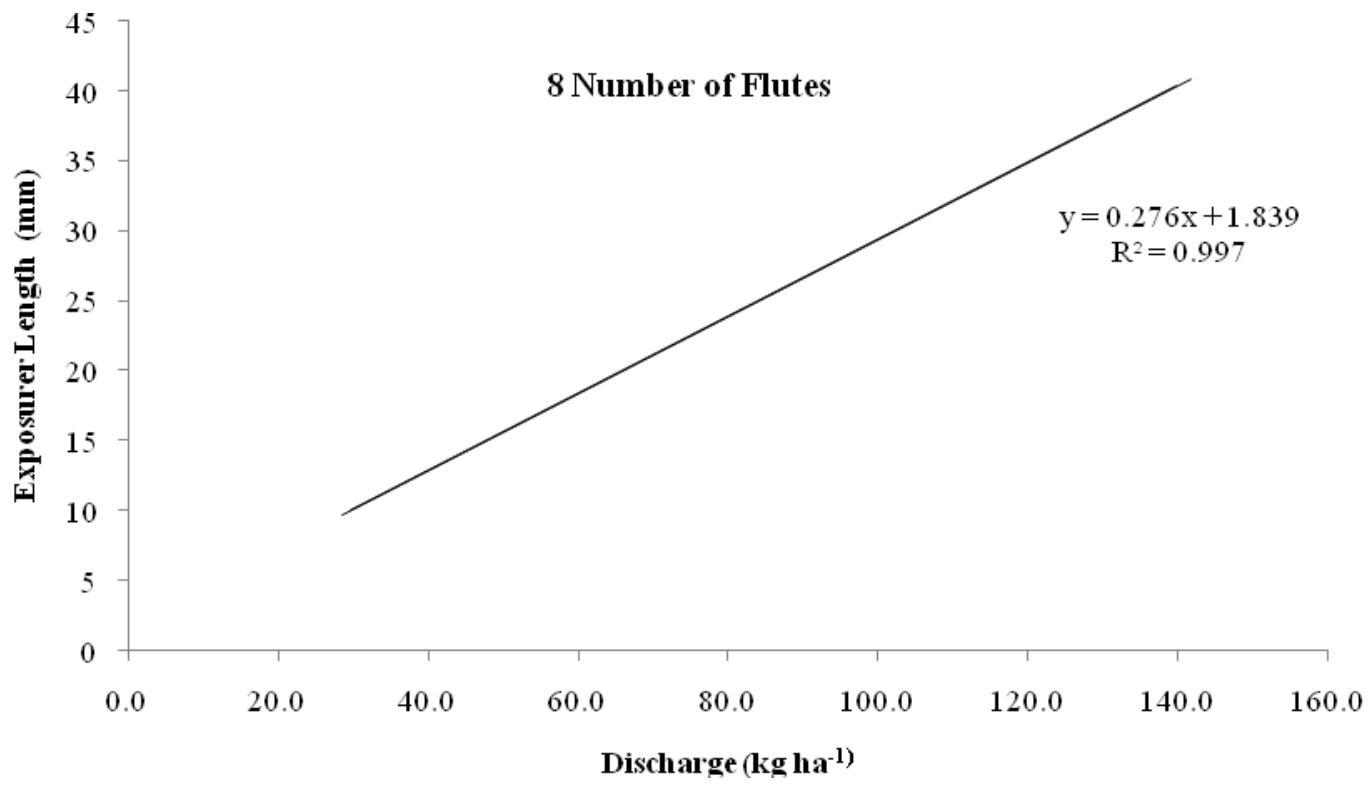

Fig.5 Performance evaluation of the developed fertilizer broadcaster
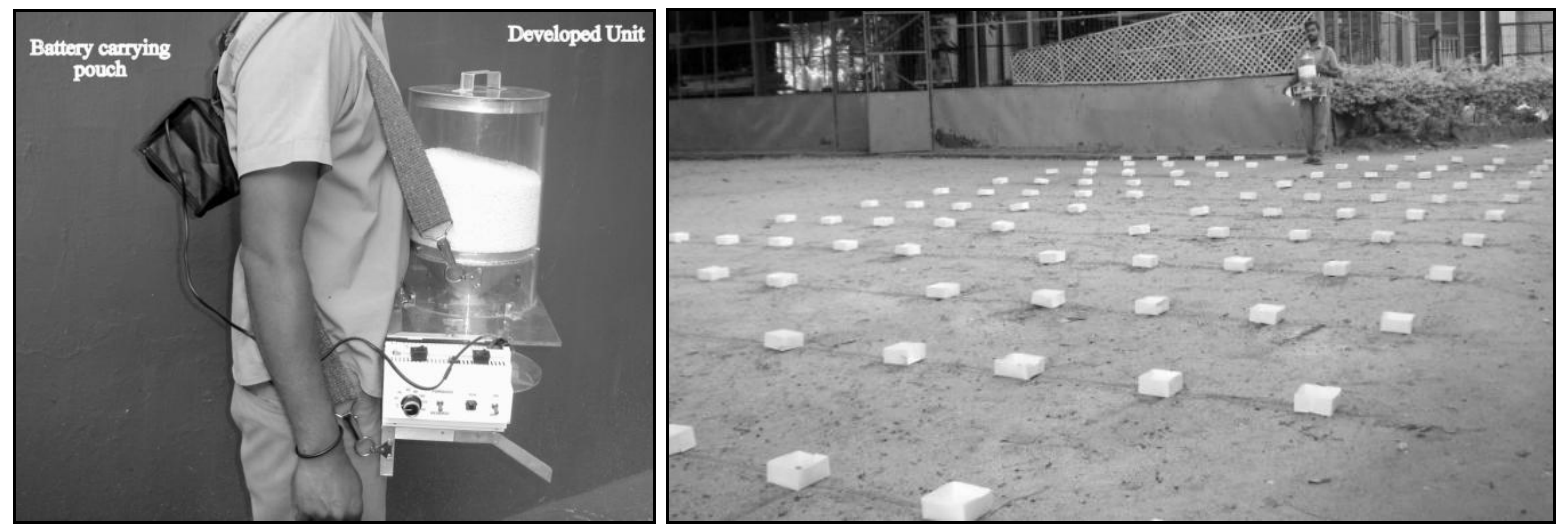

Fig.6 The graphical representation of spread patter in one direction application method

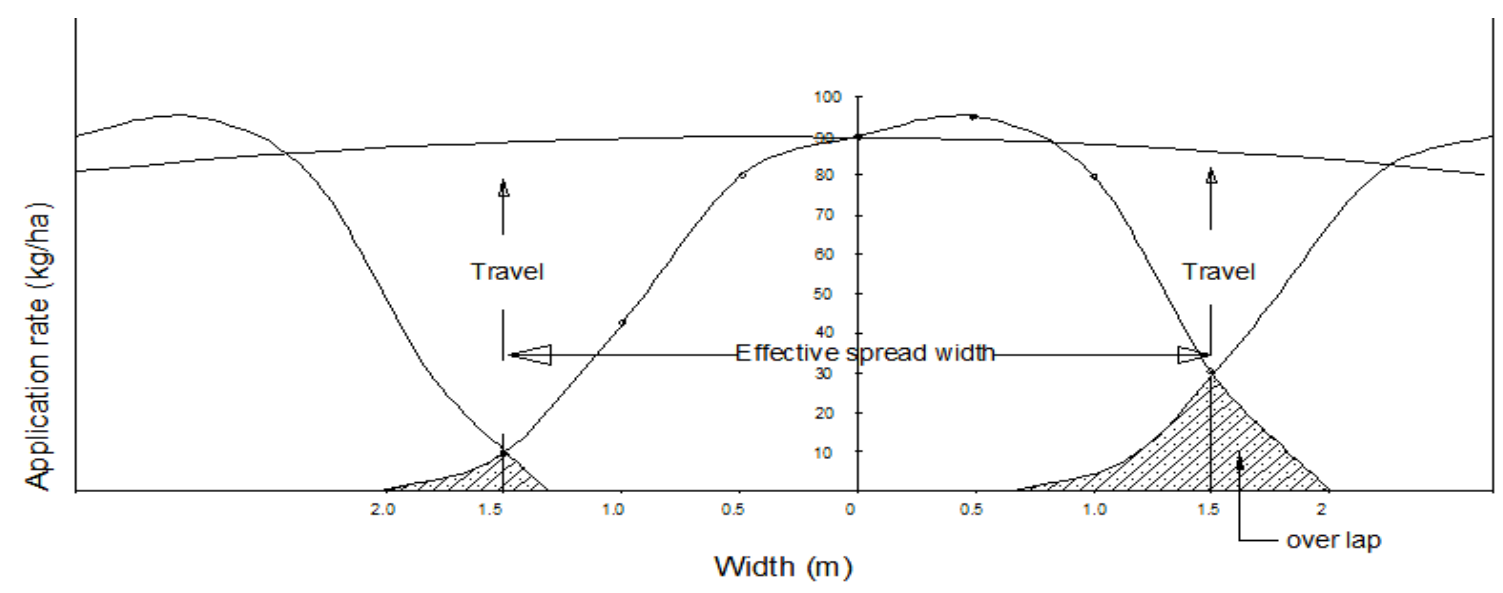


The coefficient of variation was $3.95,2.94$, 3.82 and 2.66 per cent in application rates for the exposure length of flute 10,20, 30 and 40 $\mathrm{mm}$ respectively. The previous studies support these results (Çarman, 1992; Parish, 2002; Yildirim and Kara, 2003). Effective Spread width was obtained as $3 \mathrm{~m}$ for the developed proto type.

Analysis of economic efficacy of the variable rate fertilizer broadcaster

The economic advantage of the developed variable rate fertilizer broadcaster was identified by working out the cost of operation and the field capacity. The Actual field capacity was calculated from the field trials conducted with the developed unit. The salient features of the developed unit are furnished below.

Theoretical field capacity $=0.36 \mathrm{ha} \mathrm{h}^{-1}$ Actual field capacity $=0.30$ ha h $^{-1}$ Efficiency of the machine $=$ $(0.30 / 0.36) \times 100=83$ per cent

Cost of the machine = Rs.18500/Savings in Fertilizer $=52$ per cent

The efficiency of the machine is depending on the health condition of operator, Skill of the operator, uniformity in walking speed, environment factors and field condition.

In conclusion, a battery operated variable rate fertilizer broadcaster was developed ant it consisting of storage tank, metering unit, spreading unit and variable rate controller unit was developed. The total tank capacity is $\mathbf{5 . 5}$ $\mathrm{kg}$. The empty weight of the unit is $4 \mathrm{~kg}$ total weight. Performance evaluation was conducted as per the ASAE S341 and it was observed that the application rate of 28,64 , 95 and $140 \mathrm{~kg} \mathrm{ha}^{-1}$ could be achieved for 10 , 20, 30 and $40 \mathrm{~mm}$ exposure length of flute respectively. The coefficients of variation were $3.95,2.94,3.82$ and 2.66 per cent in application rates for $10,20,30$ and $40 \mathrm{~mm}$ exposure length of flute respectively. The actual field capacity of the developed unit was observed as $0.30 \mathrm{ha} \mathrm{h}^{-1}$. The efficiency of the machine is 83 per cent. The cost of the developed machine is Rs 18500/-.

\section{Acknowledgement}

The research work was supported by the Maulana Azad National Fellowship under University Grant Commission, India. The authors are grateful to Agricultural Engineering College and Research Institute, Agricultural Machinery Research Centre, Tamil Nadu Agricultural University, Coimbatore and Department of Science and Technology, Government of India for providing facility to carry out the research.

\section{References}

Anonymous, 2016. Spreading fertiliser know how. Farming Ahead, 294(6), 22-25. http://www.farmingahead.com.au

ASAE Standards, 1999. S341.2. Procedure for Measuring Distribution Uniformity and Calibrating Granular Broadcast Spreaders. American Society of Agricultural Engineers, Madison, 756.

ASAE Standards. 2000. S341.2: Procedure for measuring distribution uniformity and calibrating broadcast spreaders. American Society of Agricultural Engineers, Madison, 758.

ASAE Standards, 2005. S341.3 FEB04 Procedure for Measuring Distribution Uniformity and Calibrating Granular Broadcast Spreaders. American Society of Agricultural Engineers, St. Joseph, Madison, 197-201.

ASAE Standards. 2009. S341.4: Procedure for Measuring Distribution Uniformity and Calibrating Granular Broadcast Spreaders. American Society of Agricultural Engineers, Madison, 762. 
Carman, K. 1992. An investigation upon the effect of feeding opening shape on the distribution pattern in disc types spreaders. Selcuk University Journal of Agricultural Faculty, 2(3), 29-38.

Ganesh, C., B. 2009. Economics of variable rate nitrogen application in Florida citrus grove. Tree and forestry science and biotechnology, 3 (special issue), 164-168.

Md. Abdul Wohab, Yam Kanta Gaihre, Ziauddin A.T.M. and Hoque, M.A. 2017. Design, Development and Field Evaluation of Manual-Operated Applicators for Deep Placement of Fertilizer in Puddled Rice Fields, Agricultural Research, 6(3):259-266. DOI 10.1007/s40003-017-0267-5

Parish, R.L. 2002. Rate setting effects on fertilizer spreader distribution patterns. Applied Engineering in Agriculture.,
18, 301-304.

R.N.A.M. Regional Network for Agricultural Machinery. $\quad 1991 . \quad$ Agricultural Machinery Design and Data Hand Book (Seeders and Planters), 83-93.

Varshney, B.P., Gajendra Singh, Bhagwansingh and Singh, K.N. 1967. Development and evaluation of a hand operated centrifugal broadcaster. Agricultural Engineering, 14(1), 1-6.

Wolf, D., D. and Smith, E., S. 1979. Uniformity of seed and fertilizer distribution with a hand operated spinning spreader. Transaction of the ASAE, $761-763$.

Yildirim, Y. and Kara, M. 2003. Effect of vane height on distribution uniformity in rotary fertilizer spreaders with different flow rates. Applied Engineering in Agriculture, 19, 19-23.

\section{How to cite this article:}

Edwin Benjamin, D. Anatha Krishnan and Kavitha, R. 2019. Development of Fertilizer Broadcaster with Electronically Controlled Fluted Roller Metering Mechanism for Paddy Crop. Int.J.Curr.Microbiol.App.Sci. 8(04): 2694-2703. doi: https://doi.org/10.20546/ijcmas.2019.804.313 